\title{
QUALIDADE DA CARNE DE SUÍNOS SUBMETIDOS A DIETAS COM DIFERENTES NIVÉIS DE RACTOPAMINA
}

\author{
MEAT QUALITY OF FINISHING PIGS FED WITH DIFFERENT RACTOPAMINE LEVELS \\ Leal, R.S. ${ }^{1 *}$; Cantarelli, V.S. ${ }^{2 A}$; Mattos, B.O. ${ }^{2 B}$; Carvalho, G.C. ${ }^{3}$; Pimenta, M.E.S.G. ${ }^{1 A}$ \\ e Pimenta, C.J. ${ }^{\text {B }}$
}

\begin{abstract}
'Departamento de Ciência dos Alimentos.Universidade Federal de Lavras (UFLA). Lavras. Brasil. *renato.quimicaufla@hotmail.com; Amaria.emilia@dca.ufla.br; ${ }^{B}$ carlospimenta@proplag.ufla.br 2Departamento de Zootecnia. Universidade Federal de Lavras (UFLA).Lavras. Brasil.Avinicius@dzo.ufla.br; Bmattos.bo@gmail.com

${ }^{3}$ Departamento de Ciências Veterinárias. Universidade Federal de Lavras (UFLA). Lavras. Brasil. guilherme-cleto@hotmail.com
\end{abstract}

\section{PaLAVRAS ChaVE ADICIONAIS}

Copa suína. Lombo suíno. Oxidação lipídica.

\section{RESUMO}

O experimento foi conduzido no Departamento de Zootecnia da Universidade Federal de Lavras com o objetivo de avaliar características químicas, físicas e sensoriais da carne de suínos recebendo diferentes níveis de ractopamina na dieta, no período de 28 dias. Foram utilizados 72 suínos híbridos, sendo 30 machos castrados e 30 fêmeas, selecionados para alta deposição de carne, com peso inicial de $84,27 \pm 2,26 \mathrm{~kg}$. O delineamento experimental foi em bloco casualizado, com 6 tratamentos $(0,3,6,9,12$ e $15 \mathrm{ppm}$ de ractopamina) e 6 repetições, com a parcela experimental representada por 1 macho e 1 fêmea. A adição de ractopamina nas dietas dos suínos nos níveis testados melhorou a composição química tanto do lombo quanto da copa, contribuindo para uma maior deposição proteica e uma menor porcentagem de lipídeos nos cortes. Nas características físicas os níveis mais altos de ractopamina comprometeram a textura e alteraram a cor, além da aceitação pelos consumidores. Já em relação à estabilidade oxidativa, tanto para os lombos armazenados sob resfriamento quanto sob congelamento, a adição de ractopamina às dietas de suínos em terminação auxiliou na prevenção da oxidação lipídica.

\section{SUMMARY}

The experiment was conducted in the

\author{
AdDITIONAL KEYWORDS \\ Boston butt. Lipid oxidation. Pork loin.
}

Department of Animal Science of the Federal University of Lavras. The objectives were to obtain chemical, physical and sensory characteristics of pork meat receiving different levels of ractopamine in the diet, in the period of 28 days. Sixty hybrids pigs were used, being 30 castrated males and 30 females, selected for high deposition of lean meat, with initial weight of $84,27 \pm 2,26 \mathrm{~kg}$. The experimental design was a completely randomized block design with six treatments $(0,3$, $6,9,12$ and 15 ppm of ractopamine) and 6 repetitions with the experimental plot represented by a male and a female. The addition of ractopamine in the diets of the pigs at the levels tested improved the chemical composition both for the loin as for the cup, contributing to greater protein deposition and a lower percentage of lipids in the cuts. In physical characteristics the highest levels of ractopamine agreed to texture and changed the color, in addition to the acceptance by consumers. Already in relation to oxidative stability, both for the loins stored under refrigeration as under freezing, the addition of ractopamine diets for pigs in the finishing phase helped in the prevention of lipid oxidation.

\section{INTRODUÇÃO}

Priorizando-se segurança alimentar, a produção de carne suína de qualidade nutricional, sensorial e tecnológica tem aten- 


\section{LEAL, CANTARELLI, MATTOS, CARVALHO, PIMENTA E PIMENTA}

dido a demanda por meio de constantes avanços no melhoramento genético para estas características, ao mesmo tempo em que são disponibilizados vários recursos nutricionais para a otimização destes alvos.

Dentre estes recursos nutricionais, a utilização da ractopamina, um agonista $\beta$ adrenérgico, tem ocupado lugar de destaque, uma vez que este aditivo promove aumento no crescimento muscular, acréscimo de proteína (See et al., 2004) aumento no rendimento de carcaça (Marchant-Forde et al., 2003), e na porcentagem de proteína bruta (Garbossa, 2010). Atua em vias metabólicas específicas, especialmente nos metabolismos protéico, lipídico e de carboidratos, redirecionando os nutrientes da dieta e favorecendo a síntese protéica em detrimento da deposição de tecido adiposo na carcaça (Gunawan et al., 2007; Watkins et al., 1990).

Sabendo que são muitos os benefícios conhecidos desta classe de droga sobre o desempenho e as características da carcaça, o presente trabalho teve como objetivo avaliar os efeitos do uso de diferentes concentrações de ractopamina na dieta de suínos em terminação sobre características químicas, físicas e sensoriais além da estabilidade oxidativa da carne.

\section{MATERIALEMÉTODOS}

O experimento foi conduzido no Centro Experimental de Suínos do Departamento de Zootecnia da Universidade Federal de Lavras. As análises foram realizadas no Laboratório Central de Análises do Departamento de Ciências dos Alimentos.

$\mathrm{O}$ delineamento experimental foi em blocos casualizados, com 6 tratamentos (níveis de 0, 3, 6, 9, 12 e 15 ppm de ractopamina) e 6 repetições.

Foram utilizados 60 animais, sendo 30 suínos machos castrados e 30 fêmeas,

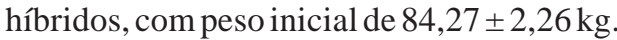
Estes foram alojados em galpão de terminação em baias de piso de concreto $(2,3 \times 1,5$ m), dotadas de comedouros semiautomáticos e bebedouros tipo chupeta. A unidade experimental foi constituída por cada animal, sendo a ração e água fornecidos à vontade.

As dietas experimentais foram formuladas à base de milho e farelo de soja, suplementadas com vitaminas, minerais e aminoácidos, de forma a atender as exigências sugeridas pela linhagem genética (tabela I)

No abate, foi empregada a insensibilização elétrica com tensão, variando na faixa entre $220 \pm 20 \mathrm{~V}$ e $60 \mathrm{hz}$ de frequência. A insensibilização foi aplicada com o animal no limitador e um tempo de contato dos eletrodos na cabeça do animal (posicionados na base das orelhas) entre um a dois segundos. Após 45 minutos do abate, as medidas de $\mathrm{pH}$ ( $\mathrm{pH}$ inicial) foram realizadas em todos os animais no músculo Longissimus dorsi (na altura da última costela). Depois de 24 horas e resfriamento da carcaça a $2 \pm$ $1^{\circ} \mathrm{C}$ foi realizada a medida do $\mathrm{pH}$ final.

Após 24 horas de armazenamento, as amostras de carne foram coletadas secciononando-se a carcaça entre a última vértebra torácica e a primeira lombar. Foram retiradas no sentido caudal, amostras dos músculos Longissimus dorsi (lombo) e Longissimus, Spinalis dorsi, Rhomboideus (copa). As amostras foram embaladas, identificadas e armazenadas em caixas térmicas e levadas até o Laboratório Central de Análises. Neste laboratório, os músculos foram seccionados, sequencialmente, através de cortes transversais e retirou-se amostras de aproximadamente $2,5 \mathrm{~cm}$ de espessura, que foram embaladas e identificadas.

Para avaliação da composição química dos diferentes cortes (lombo e copa) parte das amostras foi moída em máquina de moer carne, para maior homogeneização. Após a homogeneização retirou-se uma alíquota para a determinação da umidade. Uma segunda alíquota foi congelada a uma temperatura $-80^{\circ} \mathrm{C}$ em um ultrafreezer e em segui- 


\section{QUALIDADE DA CARNE DE SUÍNOS ALIMENTADOS COM RACTOPAMINA}

da, liofilizada por um período de 72 horas. Após a liofilização, as amostras foram armazenadas para as determinações previstas.

Para as análises químicas utilizou-se as metodologias propostas pela Association of Oficial Analytical Chemists (AOAC, 2000).

$\mathrm{Na}$ determinação de lipídeos totais, utilizou a metodologia descrita por Folch et al. (1957).

Para determinação das perdas de líquido no descongelamento e na cocção do lombo, foram retiradas amostras (bifes) de aproxi- madamente $2,5 \mathrm{~cm}$ de espessura do músculo, obtidas sempre no mesmo ponto, para evitar variações na maciez da carne, que ocorrem naturalmente ao longo do músculo. As perdas de líquido no descongelamento (PLD) e na cocção (PLC) do lombo foram expressas em porcentagem de água perdida em relação ao peso original da amostra, utilizando-se as fórmulas a seguir (Bridi et al., 2006):

$\operatorname{PLD}(\%)=$ peso da amostra congelada - peso

Tabela I. Composição centesimal e valores calculados das dietas experimentais. (Proximate composition and calculated values of the experimental diets).

\begin{tabular}{|c|c|c|c|c|c|c|}
\hline & \multicolumn{6}{|c|}{ Níveis de ractopamina (ppm) } \\
\hline & 0 & 3 & 6 & 9 & 12 & 15 \\
\hline \multicolumn{7}{|l|}{ Ingredientes (\%) } \\
\hline Milho & 71,66 & 71,66 & 71,66 & 71,66 & 71,66 & 71,66 \\
\hline Farelo de soja & 23,70 & 23,70 & 23,70 & 23,70 & 23,70 & 23,70 \\
\hline Óleo de soja & 1,84 & 1,84 & 1,84 & 1,84 & 1,84 & 1,84 \\
\hline Fosfato bicálcico & 1,08 & 1,08 & 1,08 & 1,08 & 1,08 & 1,08 \\
\hline Calcário cálcitico & 0,80 & 0,80 & 0,80 & 0,80 & 0,80 & 0,80 \\
\hline Sal & 0,36 & 0,36 & 0,36 & 0,36 & 0,36 & 0,36 \\
\hline Premix mineral ${ }^{1}$ & 0,05 & 0,05 & 0,05 & 0,05 & 0,05 & 0,05 \\
\hline Premix vitamínico ${ }^{2}$ & 0,10 & 0,10 & 0,10 & 0,10 & 0,10 & 0,10 \\
\hline DL-Metionina $99 \%$ & 0,02 & 0,02 & 0,02 & 0,02 & 0,02 & 0,02 \\
\hline L-Lisina $78 \%$ & 0,26 & 0,26 & 0,26 & 0,26 & 0,26 & 0,26 \\
\hline L-Treonina $98 \%$ & 0,11 & 0,11 & 0,11 & 0,11 & 0,11 & 0,11 \\
\hline Tylan $^{3}$ & 0,02 & 0,02 & 0,02 & 0,02 & 0,02 & 0,02 \\
\hline Cloridrato de ractopamina 2,05 \% & 0,00 & 0,015 & 0,030 & 0,045 & 0,060 & 0,075 \\
\hline \multicolumn{7}{|l|}{ Composição calculada } \\
\hline Proteína bruta (\%) & 16,06 & 16,06 & 16,06 & 16,06 & 16,06 & 16,06 \\
\hline $\mathrm{EM}(\mathrm{kcal} / \mathrm{kg})$ & 3300 & 3300 & 3300 & 3300 & 3300 & 3300 \\
\hline Lisina digestível (\%) & 1,002 & 1,002 & 1,002 & 1,002 & 1,002 & 1,002 \\
\hline Metionina digestível (\%) & 0,267 & 0,267 & 0,267 & 0,267 & 0,267 & 0,267 \\
\hline Treonina digestível (\%) & 0,661 & 0,661 & 0,661 & 0,661 & 0,661 & 0,661 \\
\hline Fósforo disponível (\%) & 0,300 & 0,300 & 0,300 & 0,300 & 0,300 & 0,300 \\
\hline Cálcio (\%) & 0,647 & 0,647 & 0,647 & 0,647 & 0,647 & 0,647 \\
\hline
\end{tabular}

'Composição, por kg de produto: cálcio, $98800 \mathrm{mg}$; cobalto, $185 \mathrm{mg}$; cobre, $15750 \mathrm{mg}$; ferro, 26250 mg; iodo, $1470 \mathrm{mg}$; zinco, $77999 \mathrm{mg}$. ${ }^{2}$ Composição, por kg de produto: ácido fólico, 116,55 mg; ácido pantotênico, 2333, mg; biotina, 5,28 mg; niacina, $5600 \mathrm{mg}$; piridoxina, $175 \mathrm{mg}$; riboflavina, 933,3 mg; tiamina 175 mg; Vitamina A, 1225000 U.I.; Vitamina D3, 315000 U.I.; Vitamina E, 1400 mg; Vitamina K3, $700 \mathrm{mg}$; Vitamina B12, $6825 \mathrm{mg}$; selênio, $105 \mathrm{mg}$; antioxidante, $1500 \mathrm{mg} \cdot{ }^{3}$ Antibiótico à base de tilosina granulada. 


\section{LEAL, CANTARELLI, MATTOS, CARVALHO, PIMENTA E PIMENTA}

da amostra descongelada/peso da amostra congelada $\times 100$;

$\operatorname{PLC}(\%)=$ peso da amostra descongelada peso da amostra assada/peso da amostra descongelada $\times 100$.

Para avaliação da força de cisalhamento do lombo foram utilizadas as mesmas amostras anteriormente, para obtenção das perdas. A força de cisalhamento foi determinada por meio do Sistema Analisador de Textura, modelo TA.XT2 (Texture Analyser, Stable Micro Systems), utilizando a probe Warner-Bratzler Shear, conforme sugerido por Bridi et al. (2006), com algumas adaptações.

Para a determinação de cor ( $\mathrm{L}^{*}, \mathrm{a}^{*}$ e $\mathrm{b}^{*}$ ) do lombo, as leituras foram realizadas nas amostras 24 horas após o abate. As leituras dos parâmetros L* (luminosidade), a* (intensidade de vermelho) e b* (intensidade de amarelo) foram baseadas no sistema de CIELab.

A oxidação lipídica foi avaliada em diferentes cortes (lombo e copa), em duas condições de armazenamento: sob refrigeração e congelamento. O método utilizado para esta avaliação foi o do ácido 2tiobarbitúrico.

Os dados obtidos foram submetidos à ANOVA de acordo com o seguinte modelo estatísticos:

Resposta $=\mathrm{PI}+\mathrm{S}+\mathrm{R}+(\mathrm{S} \times \mathrm{R})+$ erro

onde:

$\mathrm{Pl}=$ é o peso inicial e representa o efeito da classe de peso ou do peso em si, por uma correção linear do peso inicial nas respostas observadas por análise de covariância;

$S$ é $R=$ os termos com sexo (S) e ractopamina (R) representam os efeitos dos fatores já descritos e sua interação;

erro $=0$ termo de erro associa uma distribuição normal, com erros independentes e de mesma variância (pressupostos da análise de (co)variância).

Para avaliação dos cortes ao longo do tempo, o seguinte modelo foi utilizado:

Resposta $=\mathrm{PI}+\mathrm{S}+\mathrm{R}+(\mathrm{S} \times \mathrm{R})+\mathrm{e} 1+\mathrm{T}+(\mathrm{S} \times \mathrm{T})$

$+(R x T)+(S x R)+(S x T x R)$ e2

em que:

$T=$ representa o efeito contínuo de tempo, incorporado por temos polinomiais;

e1= representa os desvios a nível de corte;

e2 $=$ os desvios nas medidas repetidas em um mesmo corte. Esse modelo é conhecido como parcela subdivida no tempo.

Os pressupostos da análise de variância foram verificados por inspeção e aplicação dos testes Shapiro-Wilk (para normalidade) e Bartlet (para homocedasticidade). Para interações significativas, foi estudado o efeito de ractopamina em cada sexo. O efeito do nível de ractopamina e tempo foram avaliados pelo ajuste de modelos de regressão com termos polinomiais até no máximo o segundo grau. Quando não apresentou bom ajuste, aplicou-se o teste de médias comparando todos os níveis desses fatores como nível controle (testemunha). O efeito de sexo foi comparado pelo teste $\mathrm{F}$ da análise de variância. Todas as inferências foram aplicadas ao nível nominal de significância de $5 \%$. As análises foram realizadas utilizando o programa computacional R Development Core Team (2010).

\section{RESULTADOSEDISCUSSÃO}

Não evidenciou-se interação de sexo ractopamina, nem efeito de sexo, nas variáveis de $\mathrm{pH}$ (inicial e final), características químicas e físicas do lombo. Portanto, não há evidências que apontem que os sexos respondem de maneira diferente à ractopamina em relação às variáveis estudadas.

Para o $\mathrm{pH}$ inicial e final, não se observou diferença $(p<0,05)$ entre os animais que receberam ractopamina na dieta e aqueles que receberam a dieta controle, ou seja, os animais que receberam dieta contendo 3,6 , 9,12 ou 15 ppm de ractopamina apresentaram

Archivos de zootecnia vol. 63, núm. 243, p. 510. 


\section{QUALIDADE DA CARNE DE SUÍNOS ALIMENTADOS COM RACTOPAMINA}

valores médios de $\mathrm{pH}$ inicial e final semelhantes àqueles que receberam dieta sem ractopamina (tabela II). De maneira geral, o pH inicial observado descartou a hipótese de ocorrência de carne pálida, mole e exudativa, uma anormalidade de carne geralmente observada em animais que possuem elevado potencial para ganho de peso em músculo. Vale ressaltar que machos castrados e fêmeas apresentaram valores semelhantes para essas duas variáveis e que não houve interações entre os diferentes níveis testados e o sexo ( $p>0,05)$. Os valores médios de $\mathrm{pH}$ final observado foram baixos, inclusive inferiores ao ponto isoelétrico, podendo refletir na capacidade de retenção de água da carne (tabela II).

A porcentagem de umidade no lombo mostrou-se significativamente diferente para os níveis de ractopamina testados, apresentando um efeito quadrático $(\mathrm{p}<0,05)$. A equação obtida foi:

\section{$\mathrm{UM}=72,947+0,027 \mathrm{rac}+0,002 \mathrm{rac} 2$}

Este resultado demonstrando que os níveis de ractopamina utilizados permitiram aumento na porcentagem de umidade (tabela III). Pelos contrastes elaborados entre os diferentes níveis contra o tratamento-controle (sem adição de ractopamina) (tabela III), observou-se maior porcentagem de umidade no lombo, com a adição de ractopamina em todos os níveis testados, quando comparado aos lombos dos animais que receberam a dieta controle.

Em relação à porcentagem de proteína no lombo, contrastando o uso de ractopamina com o controle, observou-se que, para todos os níveis testados, os valores médios foram maiores. Segundo Damodaran et al. (2010) a deposição de água no músculo está relacionada com a deposição de proteína. As moléculas de água ligam-se a diversos grupos nas proteínas e esses gru-

Tabela II. Valores médios para pH(inicial e final) porcentagem de umidade, proteína bruta, extrato etéreo, lipídeos totais, perda de líquido por descongelamento e cocção, parâmetros de $\operatorname{cor}\left(L^{*}, a^{*}, b^{*}\right)$ e do lombo suíno. ( $\mathrm{pH}$ mean values (initial and final), moisture content, crude protein, ether extract, total lipids, liquid losses by thawing and cooking, and color parameters $\left(\mathrm{L}^{*}, \mathrm{a}^{*}\right.$, $\mathrm{b}^{\star}$ ) of pork loin).

\begin{tabular}{lccccccc}
\hline & \multicolumn{7}{c}{ Doses de ractopamina (ppm) } \\
& 0 & 3 & 6 & 9 & 12 & 15 & CV(\%) \\
\hline pH inicial & 6,15 & 6,01 & 6,09 & 6,25 & 6,12 & 6,15 & 1,85 \\
pH final & 5,42 & 5,34 & 5,43 & 5,37 & 5,35 & 5,37 & 1,67 \\
Umidade & 72,947 & 73,049 & 73,193 & 73,381 & 74,045 & 74,982 & 0,36 \\
Proteína bruta & 17,393 & 21,428 & 21,448 & 21,436 & 22,417 & 23,518 & 1,40 \\
Extrato etéreo & 7,302 & 5,440 & 5,460 & 5,157 & 4,291 & 5,737 & 2,68 \\
Lipídeos totais & 6,644 & 3,759 & 3,827 & 3,519 & 3,270 & 4,277 & 1,95 \\
PLD & 6,159 & 5,988 & 5,817 & 5,646 & 5,475 & 5,304 & 11,51 \\
PLC & 30,912 & 27,182 & 27,481 & 25,620 & 26,922 & 29,804 & 2,95 \\
L $^{*}$ & 53,088 & 53,088 & 53,088 & 53,088 & 53,088 & 53,088 & 4,01 \\
a $^{* 1}$ & 7,320 & 6,764 & 6,484 & 6,479 & 6,75 & 7,296 & 3,75 \\
b $^{* 1}$ & 2,003 & 1,267 & 0,772 & 0,518 & 0,506 & 0,735 & 3,69 \\
Força de cisalhamento $(\mathrm{kg})^{2}$ & 3,794 & 3,867 & 4,975 & 5,688 & 5,908 & 7,124 & 2,45 \\
\hline
\end{tabular}

$\mathrm{PLD}=$ perda de líquido por descongelamento; $\mathrm{PLC}=$ perda de líquido por cocção.

pH inicial a 45 minutos após o abate; $\mathrm{pH}$ final a 24 horas após o abate.

${ }^{1}$ Regressão quadrática significativa $(p<0,05)$; ${ }^{2}$ Regressão linear significativa $(p<0,05)$. 


\section{LEAL, CANTARELLI, MATTOS, CARVALHO, PIMENTA E PIMENTA}

Tabela III. Contrastes médios para porcentagem de umidade, proteína bruta, extrato etéreo, lipídeos totais, perda de líquido por descongelamento e cocção, parâmetros de cor $\left(L^{*}, a^{*}\right.$, $\left.b^{*}\right)$ e $\mathrm{pH}$ (inicial e final) do lombo suíno. (Contrasting mean values for moisture content, crude protein, ether extract, total lipids, liquid losses by thawing and cooking, color parameters $\left(L^{*}, a^{*}, b^{*}\right)$ and $\mathrm{pH}$ (initial and final) of pork loin).

\begin{tabular}{|c|c|c|c|c|c|}
\hline \multirow[b]{2}{*}{ Contrastes $^{1}$} & \multicolumn{5}{|c|}{ Contrastes médios } \\
\hline & 3 vs. 0 & 6 vs. 0 & 9 vs. 0 & 12 vs. 0 & 15 vs. 0 \\
\hline Umidade & 0,101 & 0,246 & 0,434 & 0,664 & 0,937 \\
\hline Proteína bruta & 4,035 & 4,055 & 4,043 & 5,024 & 6,125 \\
\hline Extrato etéreo & $-1,862$ & $-1,842$ & $-2,145$ & $-3,011$ & $-1,565$ \\
\hline Lipídeos totais & $-2,884$ & $-2,817$ & $-3,125$ & $-3,373$ & $-2,366$ \\
\hline PLD & $-0,171$ & $-0,034$ & $-0,512$ & $-0,684$ & $-0,854$ \\
\hline PLC & $-3,730$ & $-3,431$ & $-5,292$ & $-3,989$ & $-1,108$ \\
\hline$L^{\star 2}$ & - & - & - & - & - \\
\hline$a^{*}$ & $-0,555$ & $-0,835$ & $-0,840$ & $-0,569$ & $-0,023$ \\
\hline$b^{*}$ & $-0,736$ & $-1,229$ & $-1,482$ & $-1,493$ & $-1,262$ \\
\hline $\mathrm{pH}_{\text {inicial }}^{2}$ & - & - & - & - & - \\
\hline $\mathrm{pH}_{\text {final }}^{2}$ & - & - & - & - & - \\
\hline
\end{tabular}

PLD= perda de líquido por descongelamento; $\mathrm{PLC}=$ perda de líquido por cocção.

${ }^{1}$ Contraste entre médias por mínimos quadrados obtidas pelo modelo final dos níveis de ractopamina contra a dieta controle. ${ }^{2}$ Contraste não significativo.

pos incluem grupos carregados (interações íon-dipolo), grupos peptídicos de cadeia principal, grupos amida de alguns aminoácidos e resíduos de proteína não polares (interação dipolo-dipolo induzida e hidratação hidrofóbica). Assim, com a inclusão de ractopamina nas dietas, ocorreu maior deposição proteica e maiores teores de umidade no músculo de suínos em terminação, corroborando com os resultados encontrados por Apple et al. (2007) e Rossi et al. (2010).

Com relação à porcentagem de extrato etéreo e lipídeos totais no lombo, pelos contrastes, representados na tabela III observou-se que adição de ractopamina na dieta de suínos, proporcionou valores menores, tanto para extrato etéreo quanto para lipídeos totais. Sendo assim, os lombos dos animais que receberam dietas com adição de ractopamina de 3 a 15 ppm, apresentaram valores menores dessas variáveis quando comparado aos lombos dos animais que receberam a dieta controle.
Para a perda de líquido no descongelamento do lombo, observou-se efeito linear $(p<0,05)$ da suplementação de ractopamina nas dietas, sendo obtida a seguinte equação:

$$
\mathrm{PLD}=6,159-0,057 \mathrm{rC}
$$

Estes resultados demonstram que o aumento na ractopamina proporciona uma diminuição na porcentagem na perda de líquido no descongelamento, atingindo $5,30 \%$ ), com a dose de $15 \mathrm{ppm}$.

Pelos contrastes, pode-se afirmar que, em média, para perda de líquido no descongelamento do lombo, a adição de ractopamina, teve efeito sobre a exudação de água.

Para perda de líquido na cocção do lombo, observou-se que nos contrastes, todos os níveis de ractopamina apresentaram diferença em relação ao controle, e pode-se afirmar que, em média, o fornecimento de ractopamina de 3 a 15 ppm, o nível que mais 
apresentou efeito foi o $9 \mathrm{ppm}$ de ractopamina, com diminuição de 5,292\%.

Em relação ao color, o parâmetro L*, não evidenciou resposta aos diferentes níveis de ractopamina, sendo o valor médio observado de 53,088. Já para os parâmetros de cor $a^{*}$ e b*, observou-se um efeito quadrático $(\mathrm{p}<0,05)$ dos níveis testados sobre estas variáveis. As equações obtidas foram para $\mathrm{a}^{*}=7,230-0,231 \mathrm{rc}+0,015 \mathrm{rc} 2 \mathrm{e} \mathrm{b}^{*}=2,003$ $0,285 \mathrm{rc}+0,013 \mathrm{rc} 2$, com o ponto de mínimo de 6,340 e 0,440 , respectivamente. Pelo contraste, pode-se afirmar que, em média, para os parâmetros $a^{*}$ e b*, todos os níveis de ractopamina, diferiram do nível 0 . Sendo o nível de 9 ppm de ractopamina, o que apresentou menor contraste em relação ao controle. Carr et al. (2005a, 2005b) e Garbossa (2010) também não observaram diferença significativa para esta variável.

Os resultados encontrados no presente trabalho mostraram que a carne em estudo, independente do nível de ractopamina utilizado enquadrou-se na classificação como carne vermelha, flácida e exudativa, refletindo provavelmente o alto grau de melhoramento empregado na formação da linhagem utilizada, que muitas vezes leva a algum nível de comprometimento da carne. Segundo Lindahl et al. (2001) os valores de L* e a*, apresentam correlações altas com o conteúdo de pigmentos e pelas formas da mioglobina quase na mesma extensão. Já a variável b* apresenta correlações altas com as formas da mioglobina e baixa correlação com o conteúdo de mioglobina. Carr et al. (2005b) avaliando também o músculo Longíssimus dorsi de suínos suplementados com 10 ppm de ractopamina encontraram resultados similares aos do presente estudo.

Foi verificado aumento linear $(\mathrm{p}<0,05)$ na força de cisalhamento do músculo Longíssimus dorsi dos suínos com o aumento dos níveis de ractopamina na dieta, ou seja, a cada 1,0 ppm de ractopamina ocorre uma variação de 235,789 gramas na força de cisalhamento de acordo com a equação:

\section{$\mathrm{FC}=235,789 \mathrm{rc}+3418,6$}

O aumento na força de cisalhamento do músculo Longíssimus dorsi de suínos que receberam dieta contendo ractopamina foi observado por diversos autores e os principais argumentos utilizados para explicá-lo foram: a ractopamina é responsável pelo aumento do diâmetro da fibra muscular (Carr et al., 2005a, 2005b; Wood et al., 1994) e possivelmente pela redução da atividade da enzima proteolítica calpaína (Wood et al., 1994). Segundo Xiong et al. (2006), a redução da maciez é explicada pela redução na degradação de proteína e quebra de miofibrilas nos músculos de suínos alimentados com ração contendo ractopamina.

Com relação à porcentagem de umidade na copa, não evidenciou-se nenhuma resposta aos níveis de ractopamina, sendo o valor médio observado de 61,464\%. Para a porcentagem de proteína bruta na copa, observou-se que nos contrastes os níveis de ractopamina foram todos diferentes do controle, e pode-se afirmar que, em média, a porcentagem de proteína bruta na copa, o fornecimento de ractopamina de 3 a $15 \mathrm{ppm}$, o nível que mais apresentou efeito contra o controle foi o de $15 \mathrm{ppm}$ de ractopamina, propiciando um aumento de 3,316\% na proteína bruta (tabela IV).

Com relação à porcentagem de extrato etéreo na copa suína, observou-se que nos contrastes, representados na tabela $\mathbf{V}$, os níveis de ractopamina foram todos diferentes do nível 0, e pode-se afirmar, portanto, que o fornecimento de ractopamina de 3 a 15 ppm, o nível que mais apresentou efeito contra o nível 0 foi o de $15 \mathrm{ppm}$ de ractopamina, com uma redução de 3,336 \% no valor médio apresentado na dieta controle (tabela V).

Os resultados apresentados para lipídeos totais para a copa suína foram bastante semelhantes aos descritos para extrato etéreo. Nos diferentes níveis de ractopamina testados, a dose de $15 \mathrm{ppm}$ apresentou resposta semelhante tanto para porcentagem 


\section{LEAL, CANTARELLI, MATTOS, CARVALHO, PIMENTA E PIMENTA}

Tabela IV. Valores médios para porcentagem de umidade $(U)$, proteína bruta $(P B)$, extrato etéreo (EE) e lipídeos totais (LT) da copa suína. (Mean values for moisture content (U), crude protein (PB), ether extract (EE), and total lipids (LT) of boston butt).

\begin{tabular}{lcccccc}
\hline \multicolumn{6}{c}{ Doses de ractopamina (ppm) } \\
& 0 & 3 & 6 & 9 & 12 & 15 \\
\hline U & 61,46 & 61,46 & 61,46 & 61,46 & 61,46 & 61,46 \\
PB & 18,33 & 19,46 & 19,38 & 19,54 & 20,72 & 21,53 \\
EE & 16,62 & 15,16 & 14,17 & 14,88 & 14,23 & 13,28 \\
LT & 12,06 & 12,06 & 11,36 & 12,01 & 11,79 & 10,55 \\
\hline
\end{tabular}

de extrato etéreo quanto para lipídeos totais quando comparados com os animais que receberam a dieta controle.

Pode-se notar que no presente estudo a adição de ractopamina de 0 a 15 ppm levou um aumento na porcentagem de proteína como é observado na tabela III, no qual os animais que receberam a ração controle apresentaram 18,3\% contra $21,5 \%$ dos animais que receberam $15 \mathrm{ppm}$ de ractopamina na ração.

Ao analisar a oxidação lipídica dos lombos dos animais, armazenados sob resfriamento, nos tempos 0 e $12^{\circ}$ dia, observou-se diferença significativa nos níveis $6,9,12$ e 15 ppm de ractopamina na dieta em relação ao controle, sendo que todos os níveis empregados resultaram em menores valores de dialdeído malônico em relação ao controle (tabela VI).

Os lombos dos animais que receberam 3 ppm de ractopamina na dieta não deferiram dos lombos dos animais que receberam a dieta controle. No $4^{\circ}$ e $8^{\circ}$ dia de armazenamento sob resfriamento, os lombos dos animais que receberam ractopamina na dieta apresentaram valores significamente inferiores de dialdeído malônico $(\mathrm{p}<0,05)$ que os lombos dos animais que receberam a dieta sem ractopamina. Pode-se inferir, portanto, que o fornecimento de ractopamina nos níveis de 6,9,12 e 15 ppm na dieta de suínos em terminação, ajudou a prevenir a oxidação
Tabela V. Contraste médio para porcentagem de umidade $(U)$, proteína bruta $(P B)$, extrato etéreo (EE), lipídeos totais (LT) da copa suína. (Contrasting mean values for moisture content $(U)$, crude protein (PB), ether extract (EE) and total lipids ( $\mathrm{LT}$ ), and $\mathrm{pH}$ (initial and final) of boston butt).

\begin{tabular}{lccccc}
\hline \multicolumn{6}{c}{ Contrastes médios } \\
& 3 vs. 0 & 6 vs. 0 & 9 vs. 0 & 12 vs. 0 & 15 vs. 0 \\
\hline U & - & - & - & - & - \\
PB & 1,121 & 1,048 & 1,207 & 2,383 & 3,196 \\
EE & $-1,455$ & $-2,445$ & $-1,732$ & $-2,391$ & $-3,336$ \\
LT & $-0,000$ & $-0,695$ & $-0,045$ & $-0,268$ & $-1,508$ \\
\hline
\end{tabular}

lipídica do lombo, e consequentemente, prevenindo o aparecimento de odores e gostos característicos do ranço.

No entanto, o tempo de armazenamento sob resfriamento levou um aumento nos valores de concentração de dialdeído em todos os níveis $(0,3,6,9,12$ e 15 ppm), ao longo do tempo,sendo entretanto, mais acentuado nos lombos dos animais que receberam a dieta controle, apresentando concentração média de MDA igual a $0,43 \mathrm{mg} / \mathrm{kg}$

Tabela VI. Concentrações de dialdeído malônico (MDA, $\mathrm{mg} / \mathrm{kg}$ ) de lombos de suínos em terminação, recebendo ractopamina na dieta, armazenados sob resfriamento durante os períodos de 0, 4, 8 e 12 dias. (Concentrations of malonic dialdehyde (MDA mg/kg) of the loins from finishing pigs receiving dietary ractopamine, and stored under cooling during periods of $0,4,8$ and 12 days).

\begin{tabular}{ccccccc}
\hline \multicolumn{8}{c}{ Doses de ractopamina (ppm) } \\
& 0 & 3 & 6 & 9 & 12 & 15 \\
\hline 0 & 0,16 & 0,15 & $0,13^{*}$ & $0,10^{*}$ & $0,20^{*}$ & $0,14^{*}$ \\
4 & 0,28 & $0,24^{*}$ & $0,25^{*}$ & $0,23^{*}$ & $0,25^{*}$ & $0,26^{*}$ \\
8 & 0,33 & $0,36^{*}$ & $0,35^{*}$ & $0,34^{*}$ & $0,34^{*}$ & $0,34^{*}$ \\
12 & 0,43 & 0,42 & $0,35^{*}$ & $0,35^{*}$ & $0,35^{*}$ & $0,34^{*}$
\end{tabular}

*Medias seguidas de asterisco em cada tempo diferem do nível 0 de ractopamina. 
Tabela VII. Concentrações de dialdeído malônico (MDA, $m g / k g$ ) de lombos de suínos em terminação, recebendo ractopamina na dieta, armazenados sob congelamento $d u$ rante os períodos de 0,15, 30, 60 e 90 dias. (Concentrations of malonic dialdehyde (MDA mg/ $\mathrm{kg}$ ) of the loins from finishing pigs receiving dietary ractopamine stored under cooling during periods of $0,15,30,60$ and 90 days).

\begin{tabular}{|c|c|c|c|c|c|c|}
\hline & & Dose & de rac & opamin & (ppm) & \\
\hline & 0 & 3 & 6 & 9 & 12 & 15 \\
\hline 0 & 0,20 & $0,14^{*}$ & $0,16^{*}$ & $0,11^{*}$ & $0,14^{*}$ & 0,11 \\
\hline 15 & 0,07 & $0,06^{*}$ & $0,05^{*}$ & $0,04^{*}$ & $0,03^{*}$ & 0,05 \\
\hline 30 & 10,09 & $0,07^{*}$ & $0,05^{*}$ & $0,04^{*}$ & $0,03^{*}$ & 0,05 \\
\hline 60 & 10,14 & $0,16^{*}$ & $0,12^{*}$ & $0,12^{*}$ & $0,11^{*}$ & $0,07^{\prime}$ \\
\hline 90 & 0,23 & $0,17^{*}$ & $0,14^{*}$ & $0,12^{*}$ & $0,12^{*}$ & 0,12 \\
\hline
\end{tabular}

*Medias seguidas de asterisco em cada tempo diferem do nível 0 de ractopamina $(p<0,05)$.

no $12^{\circ}$ dia. De acordo com Dunshea et al. (2005), o limite de concentração de dialdeído malônico para conferir rancidez para carne suína fresca é de $0,5 \mathrm{mg}$ de MDA/ $\mathrm{kg}$ de amostra. Acima deste valor, Leick et al. (2010), afirmam que a ingestão destes produtos passa a ser desagradável para os consumidores.

Ao analisar a oxidação lipídica dos lombos armazenados sob congelamento, observou-se diferença $(\mathrm{p}<0,05)$ em todos os tempos ( 0 a 90 dias) para os níveis 3, 6, 9, 12 e 15 ppm de ractopamina na dieta em relação ao controle, ou seja, em todos os tempos de avaliação os níveis de dialdeído malônico foram inferiores nos lombos de animais que receberam ractopamina na dieta quando comparados com os lombos de animais que receberam a dieta controle (tabela VII).

Nos lombos dos animais armazenados sob congelamento, evidenciou-se que a concentração de MDA foi reduzida quando houve adição de ractopamina nas dietas dos animais. Ao longo do tempo de armazenamento sob congelamento, os valores médios de MDA nos lombos aumen- taram, sendo, entretanto, mais evidente nos lombos dos animais que receberam a dieta controle.

A concentração de MDA nos lombos dos animais recebendo a dieta controle foi de $0,23 \mathrm{mg} / \mathrm{kg}$ aos 90 dias de congelamento, já os lombos dos animais que receberam dietas contendo ractopamina ficam em média $0,14 \mathrm{mg} / \mathrm{kg}$ de MDA. Portanto, as concentrações de MDA ficaram abaixo do que a literatura cita como detectáveis pelos consumidores, sendo assim, o lombo de suínos alimentados com ractopamina nos níveis de 3, 6, 9, 12 e 15 ppm podem ser armazenados sob congelamento por um período de até 90 dias sem que haja deterioração da sua qualidade, sob o ponto de vista de oxidação lipídica.

Ao estudar a oxidação lipídica das copas armazenadas sob resfriamento observou-se que todos os níveis de adição de ractopamina proporcionaram em todos os tempos avaliados menores valores de dialdeído malônico quando comparados ao controle, conforme representado na tabela VIII.

Nas copas dos animais armazenadas sob

Tabela VIII. Concentrações de dialdeído malônico (MDA, $\mathrm{mg} / \mathrm{kg}$ ) de copa de suínos em terminação, recebendo ractopamina na dieta, armazenados sob resfriamento durante os períodos de 0, 4, 8 e 12 dias. (Concentrations of malonic dialdehyde (MDA mg/kg) of the boston butt from finishing pigs receiving dietary ractopamine, and stored under cooling during periods of $0,4,8$ and 12 days).

\begin{tabular}{ccccccc}
\hline \multicolumn{8}{c}{ Doses de ractopamina (ppm) } \\
& 0 & 3 & 6 & 9 & 12 & 15 \\
\hline 0 & 0,20 & $0,15^{*}$ & $0,16^{*}$ & $0,11^{*}$ & $0,14^{*}$ & $0,11^{*}$ \\
4 & 0,34 & $0,19^{*}$ & $0,21^{*}$ & $0,20^{*}$ & $0,21^{*}$ & $0,17^{*}$ \\
8 & 0,57 & $0,46^{*}$ & $0,26^{*}$ & $0,27^{*}$ & $0,28^{*}$ & $0,23^{*}$ \\
12 & 1,24 & $0,64^{*}$ & $0,39^{*}$ & $0,49^{*}$ & $0,53^{*}$ & $0,53^{*}$
\end{tabular}

*Medias seguidas de asterisco em cada tempo diferem do nível 0 de ractopamina. 


\section{LEAL, CANTARELLI, MATTOS, CARVALHO, PIMENTA E PIMENTA}

resfriamento, notou-se que as provenientes de animais que receberam dietas sem adição de ractopamina no $8^{\circ}$ dia, já apresentaram valores superiores aos citados na literatura como indesejáveis, por conferir rancidez à carne (Dunshea et al., 2005), pois apresentaram concentração de MDA de 0,570 $\mathrm{mg} / \mathrm{kg}$. Já as copas dos animais armazenadas sob resfriamento originadas de animais que receberam dietas contendo ractopamina nos níveis de 3, 6, 9, 12 e 15 ppm, o prazo de armazenamento sob resfriamento foi maior, se prolongando até o $8^{\circ}$ dia, para todos os níveis testados.

Para a copa sob congelamento (tabela IX), no tempo 0 de armazenamento, observou-se diferença $(\mathrm{p}<0,05)$ para os animais que receberam 3,6 e 12 ppm de ractopamina na dieta, os quais apresentaram menor concentração de dialdeído malônico (MDA), que as copas dos animais que receberam a dieta controle, enquanto que ao se utilizar 9 ou 15 ppm de ractopamina na dieta, os valores de dialdeído malônico das copas foram semelhantes aos encontrados para a dieta

Tabela IX. Concentrações de dialdeído malônico malônico (MDA, mg/kg) de copas de suínos em terminação, recebendo ractopamina na dieta, armazenados sob congelamento durante os períodos de 0, 15, 30, 60 e 90 dias. (Concentrations of malonic dialdehyde (MDA $\mathrm{mg} / \mathrm{kg}$ ) of the boston butt from finishing pigs receiving dietary ractopamine, and stored under cooling during periods of $0,15,30$, 60 and 90 days).

\begin{tabular}{ccccccc}
\hline & \multicolumn{6}{c}{ Doses de ractopamina (ppm) } \\
& 0 & 3 & 6 & 9 & 12 & 15 \\
\hline 0 & 0,16 & $0,15^{*}$ & $0,15^{*}$ & 0,16 & $0,15^{*}$ & 0,16 \\
15 & 0,13 & 0,13 & 0,13 & $0,12^{*}$ & $0,11^{*}$ & $0,11^{*}$ \\
30 & 0,14 & 0,14 & 0,14 & $0,12^{*}$ & $0,12^{*}$ & $0,11^{*}$ \\
60 & 0,15 & 0,15 & 0,15 & $0,13^{*}$ & $0,12^{*}$ & $0,13^{*}$ \\
90 & 0,17 & $0,15^{*}$ & $0,15^{*}$ & $0,13^{*}$ & $0,12^{*}$ & $0,13^{*}$
\end{tabular}

*Medias seguidas de asterisco em cada tempo diferem do nível 0 de ractopamina. controle. Nos tempos 15, 30 e 60 dias de armazenamento, as copas dos animais que receberam dietas com 3 e 6 ppm apresentaram a concentração de dialdeído malônico semelhantes e receberam a dieta controle.

Aos 30 e 60 dias de armazenamento sob congelamento, as copas dos animais que receberam dietas contendo os níveis de 9 , 12 e 15 ppm de ractopamina, apresentaram valores médios menores de concentração de MDA, que as copas dos animais que receberam a dieta controle $(p<0,05)$. Aos 90 dias, as copas dos animais que receberam dietas contendo os níveis de 3, 6, 9, 12 e 15 ppm de ractopamina, apresentaram valores médios menores de concentração de MDA, que as copas dos animais que receberam a dieta controle $(p<0,05)$.

Apesar da diferença apresentada entre as médias dos diferentes níveis e as médias do tratamento controle, as concentrações de MDA, tanto das copas dos animais que receberam dietas com ractopamina quanto as copas dos animais que receberam a dieta controle, ficaram abaixo do que a literatura cita como detectáveis pelos consumidores. Sendo assim, da mesma forma como observado para o lombo, as copas de suínos que receberam ractopamina nas dietas nos níveis de 3 a 15 ppm podem ser armazenados sob congelamento por um período de 90 dias, sem que haja deterioração da sua qualidade, no ponto de vista de estabilidade oxidativa.

Pode-se afirmar que a ractopamina reduz a concentração de MDA nos cortes (lombo e copa) dos suínos, armazenados sob resfriamento, chegado a $19 \%$ nos lombos e $68 \%$ nas copas dos animais que receberam ractopamina na dieta nos níveis de 3, 6, 9, 12 e $15 \mathrm{ppm}$, quando comparados aos cortes dos suínos que receberam a dieta controle. Já quando os cortes foram armazenados sob congelamento, a concentração de MDA apresenta redução de $46 \%$ no lombo e $26 \%$ na copa.

Em suma, ao analisar num todos os valores médios de MDA, do lombo e copa dos 


\section{QUALIDADE DA CARNE DE SUÍNOS ALIMENTADOS COM RACTOPAMINA}

animais, pode-se afirmar que o fornecimento de ractopamina para suínos em terminação previne oxidação, diminuindo e assim a rancidez, e a presença de radicais hidroperóxidos lipídicos. A reação de peroxidação de lipídeos com proteínas costuma ter efeito direto sobre o valor nutricional das proteínas (Damodaran et al., 2010), e pode levar, também, a odores indesejáveis.

\section{CONCLUSÕES}

$\mathrm{A}$ adição de ractopamina na dieta dos suínos nos níveis testados modificó a característica química tanto do lombo quanto da copa, contribuindo para maior deposição protéica e menor porcentagem de lipídeos nos cortes. Nas características físicas os

\section{BIBLIOGRAFIA}

AOAC. 2000. Association of Official Analytical Chemists. Official methods of analysis of AOAC international. Washington, DC. 17: 3000.

Apple, J.K.; Rincker, P.J.; Mckeith, F.K.; Carr, S.N.; Armstrong, T.A. and Matzat, P.D. 2007. Review: meta-analysis of the ractopamina response in finishing swine. Profess Anim Scient (ARPAS), 23: 179-196.

Bridi, A.M.; Oliveira, A.R.; Fonseca, N.A.N.; Shimokomaki, M.; Coutinho, L.L. e Silva, C.A. 2006. Efeito do genótipo halotano, da ractopamina e do sexo do animal na qualidade da carne suína. Rev Bras Zooctecn, 35: 2027-2033.

Carr, S.N.; Rincker, P.J.; Killefer, J.; Baker, D.H.; Ellis, M. and McKeith, F.K. 2005a. Effects of different cereal grains and ractopamine hydrochloride on performance, carcass characteristics, and fat quality in late-finishing pigs. J Anim Sci, 83: 223-230.

Carr, S.N.; Ivres, D.J.; Anderson, D.B.; Jones, D.J.; Mowrey, D.H.; England, M.B.; Killefer, J.; Rincker, P.J. and Mckeith, F.K. 2005b. The effects of ractopamine hydrochloride on lean carcass yields and pork quality characteristics. $J$ Anim Sci, 83: 2886-2893.

Damodaran, S.; Parkin, K.L. y Fennema, O.R. 2010. Química de alimentos de Fenemma. $4^{\mathrm{a}}$ ed. Artmed. Porto Alegre. 900 pp. níveis mais altos de ractopamina comprometeram a textura e alteraram a cor, além da aceitação pelos consumidores. Já em relação à estabilidade oxidativa, tanto para os lombos armazenados sob resfriamento quanto sob congelamento, a adição de ractopamina às dietas de suínos em terminação auxiliou na prevenção da oxidação lipídica. Assim, aconselha-se que a inclusão de ractopamina em dietas de suínos na fase de terminação não seja superior a 9 ppm.

\section{AGRADECIMENTOS}

Os autores deste trabalho agradecem ao Conselho Nacional de Desenvolvimento Científico e Tecnológico - CNPq, pelo financiamento desta pesquisa.

Dunshea, F.R.; Souza, D.N.D.; Pethick, D.W.; Harper, G.S. and Warner, R.D. 2005. Effects of dietary factors and other metabolic modifiers on quality and nutritional value of meat. Meat Sci, 71: 8-38.

Folch, J.; Lees, M. and Sloanne Stanley, G.H. 1957. A simple method for the isolation and purification of total lipide from animal tissues. $J$ Biol Chem, 226: 497-509.

Garbossa, C.A.P. 2010. Composição química, características físicas e peroxidação lipídica da carne de suínos alimentados com diferentes níveis de ractopamina. Dissertação (Mestrado em Ciências Veterinária). Universidade Federal de Lavras. Lavras. 70 pp.

Gunawan, A.M.; Richert, B.T.; Schinckel, A.P.; Grant, A.L. and Gerrard, D.E. 2007. Ractopamine induces differential gene expression in porcine skeletal muscles. J Anim Sci, 85: 2115-2124.

Lindahl, G.; Lundstrom, K. and Tornberg, E. 2001. Contribution of pigment content, myoglobin forms and internal reflectance to the colour of pork loin and ham from pure breed pigs. Meat Sci, 59: 141-151.

Leick, C.M.; Puls, C.L.; Ellis, M.; Killefer, J.; Carr, T.R.; Scramlin, S.M.; England, M.B.; Gaines, A.M.; Wolter, B.F.; Carr, S.N. and Mckeith, F.K. 2010. Effect of distillers driep grains with solu-

Archivos de zootecnia vol. 63, núm. 243, p. 517. 


\section{LEAL, CANTARELLI, MATTOS, CARVALHO, PIMENTA E PIMENTA}

bles and ractopamina (Paylean) on quality and shelf-life of fresh pork and bacon. J Anim Sci, 88: 2751-2766.

Marchant-Forde, J.N.; Bradshaw, H.R.; MarchantForde, M.R. and Broom, D.M. 2003. A note on the effect of gestation housing environment on approach test measures in gilts. Appl Anim Behav Sci, 80: 28-296.

R Development Core Team. 2010. A language and environment for statistical computing. R Foundation for Statistical Computing. Viena. Austria.

Rossi, C.A.R.; Lovatto, P.A.; Garcia, G.G.; Lenhen, C.R.; Porolnik, G.V.; Ceron, M.S. and Lovato, G.D. 2010. Pigs fed containing ractopamina and citrus extracts: performance and carcass characteristics. Ciênc Rural, 40: 2343-2349.

See, M.T.; Armstrong, T.A. and Weldon, W.C.
2004. Effect of a ractopamine feeding program on growth performance and carcass composition in finishing pigs. J Anim Sci, 82: 24742480.

Watkins, L.E.; Jones, D.J.; Mowrey, D.H.; Anderson, D.B. and Veenhuizen, E.L. 1990. The effect of various levels of ractopamine hydrochloride on the performance and carcass characteristics of finishing swine. J Anim Sci, 68: 3588-3595.

Wood, J.D.; Wiseman, J. and Cole, D.J.A. 1994. Control and manipulation of meat quality. In: Cole, D.J.A.; Wiseman, J.; Varley, M.A. (Eds.). Principles of pig science. pp. 446-448.

Xiong, Y.L.; Gower, M.J.; Li, C.; Elmore, C.A.; Cromwell, G.L. and Lindemann, M.D. 2006. Effect of dietary ractopamine on tenderness and postmortem protein degradation of pork muscle. Meat Sci, 73: 600-604. 